\title{
E Cigarettes- Trends and Health Effects : A Review
}

\author{
Kiruthika Patturaja ${ }^{1}$ and Leelavathi. $\mathrm{L}^{2}$ \\ ${ }^{1}$ Saveetha Dental College and Hospitals, Saveetha Institute of Medical \\ and Technical sciences, Saveetha University, Chennai 600077, India \\ ${ }^{2}$ Senior Lecturer, Department of Public Health Dentistry, Saveetha Dental \\ College and Hospitals, Saveetha Institute of Medical and Technical sciences, \\ Saveetha University, Chennai 600077, India
}

\begin{abstract}
Electronic cigarettes also known as e-cigarettes are products that provide a nicotine-containing aerosol to users by heating a solution which is mainly made up of nicotine or flavoring agent. With rapid increase in use and popularity of e-cigarettes usage the health related adverse effects are not known to many. Evidence suggests that compared to conventional cigarettes, e-cigarettes have less adverse effects. Contrary, there were many clinical studies reporting various health effects of nicotine and tobacco products .Most of the results were based on short term outcomes, long term studies should be done regarding the usage and health effects of e-cigarettes. This review tends to review the trend and health effects of e-cigarettes based on existing literature articles.
\end{abstract}

KEY WORDS: E-CIGARETTES; HEALTH EFFECTS; TRENDS; SMOKING.

\section{INTRODUCTION}

Tobacco use in India is mainly of two forms, smoking (cigarettes ,Bidis) and smokeless forms (gutka, pan masala, Areca nuts). Tobacco has been estimated to cause premature death worldwide. (India. Ministry of Health and Family Welfare, 2007). Tobacco consists of various toxic and carcinogenic chemicals present in it, one of the main components is nicotine. Tobacco has been compulsively used nearly every culture into which tobacco has been introduced. According to WHO, in India 94 million men and 45 million women used tobacco in smoke or smokeless form (Bulletin of the World Health Organization, n.d.).

\section{ARTICLE INFORMATION}

*Corresponding Author: leelavathi.sdc@saveetha.com Received 4th Aug 2020 Accepted after revision 29th Sep 2020 Print ISSN: 0974-6455 Online ISSN: 2321-4007 CODEN: BBRCBA

Thomson Reuters ISI Web of Science Clarivate Analytics USA and Crossref Indexed Journal

\section{Clarivate
Analytics}

NAAS Journal Score 2020 (4.31) SJIF: 2020 (7.728)

A Society of Science and Nature Publication,

Bhopal India 2020. All rights reserved.

Online Contents Available at: http//www.bbrc.in/

Doi: http://dx.doi.org/10.21786/bbrc/13.8/133
Electronic nicotine delivery systems (ENDS) are battery powered devices that provide doses of nicotine and other additives to the user in a hand held device in a vapour form also known as vape pens, e-cigars, or vaping devices . There are multiple types of ENDS including electronic cigarettes, or e-cigarettes, as well as e-hookahs, e-cigars, and e-pipes. Some of these products are disposable varieties, while others can be refilled or recharged for repeated use (Benowitz, 2011).

E-cigarettes use a metal resistance coil to heat and aerosolized mixtures such as tobacco-specific nitrosamines, aldehydes, metals, volatile organic compounds, phenolic compounds, polycyclic aromatic hydrocarbons, and tobacco alkaloids are components of e-cigarettes but at lesser concentration than conventional cigarettes (Cheng, 2014). Some studies have reported that e-cigarettes can be used as smoking cessation therapy due to lesser concentration of tobacco components (Brown et al., 2014) while other studies debate on potential harm and ill effects of tobacco (Gornall, 2015). E-cigarettes were originally marketed in 2004, known as cig-a-likes developed by China as a less dangerous alternative to conventional cigarettes (Grana et al., 2014). 
Most electronic cigarettes release nicotine and other potentially toxic and irritating substances into the air thereby affecting the by -standers (Daynard, 2018). There is highest relative risk for cancer initiation due to smoking is the lungs and oral cavity .Two potential hazards related to e-cigarettes are acute toxic effects caused by accidental or intentional ingestion of e-cigarette liquids causing nausea, vomiting, headache, dizziness and physical injury caused by the e-cigarette device such as explosion of the device (Vakkalanka et al., 2014). Unlike cigarettes, scientific knowledge about alternative tobacco forms such as e-cigarettes, smokeless tobacco remains limited, and in most cases there is a lack of regulation. This review aims to update the trends and effects of e-cigarettes on health.

Trends on E-Cigarettes: E-cigarette have been an initiation for smoking habits among young adults who were non-smokes earliest (McMillen et al., 2014). A cohort study shows , 81\% of youth users of electronic cigarettes reported that their starter product was flavoured compared with $61 \%$ and $46 \%$ of young and adults, respectively (Villanti et al., 2017). Studies have shown that there is increased use of e-cigarettes among U.S.population (Arrazola et al., 2015) US National Youth Tobacco Survey, over 1.6 million high school students and 500000 middle school students used electronic cigarettes in 2015 (Singh, Arrazola, et al., 2016)In the United Kingdom, adult e-cigarette use has more than tripled from 700,000 users in 2012 to 2.6 million users in 2015 (Ash, 2016). The 2015 GATS-2 estimated that the prevalence of use of e cigarettes in india was $0.02 \%$ (268,000 users) (Asma et al., n.d.). Electronic cigarette advertisements on internet sites, retail stores, movies and other media are associated with growing use among students (Singh, Agaku, et al., 2016).

Modular systems (mods), containing batteries, fillable liquid tanks, and heating coils have a comparably small allowing the use of custom-made flavors and individualized settings for temperature and wattages. (Pearson et al., 2020). Advances in technology, Juul device was introduced which resembles a USB memory stick with cartridges (pods) that are exchangeable by the user and filled with flavored e-liquids (King et al., 2018). In order to deliver nicotine to the lungs, the user inhales through a mouthpiece, and the airflow triggers a sensor that then switches on the atomizer (Eisenberg et al., 2018).

\section{Adverse Health Effects}

Oral cavity: A case report shows occurrence of lichenoid reaction in oral mucosa after using e-cigarette (Reuther et al., 2016). Exclusive tobacco consumption appears to be more likely to contribute to epithelial dysplasia in precancerous condition such as leukoplakia, erythroplakia is a hallmark for cancer development (Institute of Medicine et al., 2001). Smokers have been found to have increased number of neutrophils but decreased activity which elevates the oxidative burst thus causing tissue destruction by direct toxic effect from tobacco (Shirodaria et al., 2000); thus smoking exerts a strong untoward effect on periodontal health and is a major risk factor for periodontal disease (Okamoto et al., 2006). Smokers exhibit decreased bleeding upon probing, increased clinical loss of attachment, gingival recession and tooth mobility independent of age, gender and systemic condition (Machuca et al., 2000). Smokers respond less favourably than non-smokers to nonsurgical ,surgical periodontal therapy and they have poor wound healing capacity (Preber et al., 1995).Tobacco use may directly compromise the osseointegration of root-form dental implants causing peri-implantitis and implant failure (Wallace, 2000). Long-term smoking would significantly reduce salivary flow rate and increase oral and dental disorders associated with dry mouth, especially cervical caries, gingivitis, calculus and halitosis (Rad et al., 2010). Menthol and tobacco e-liquids present in e cigarettes may alter the enamel color altering the dental aesthetics (Pintado-Palomino et al., 2019).

Respiratory system: A clinical study reported e-cigarette use is reportedly less harmful than conventional smoking and can lead to reduced cigarette consumption with subsequent improvements in status of asthma outcomes, e-cigarette can be a valid option for asthmatic patients who cannot quit smoking by conventional method (Polosa et al., 2014). Oxidants or reactive oxygen species found in cigarette smoke generated from tars are major contributors in mediating an inflammatory state, which have been implicated in the pathogenesis of diseases, such as chronic obstructive pulmonary disease (COPD) and lung cancer (Sundar et al., 2013) .Reports on parenchymal and bronchial inflammation, lung damage and toxicity (e.g., lipoid pneumonia, hypersensitivity pneumonitis as well as impaired systemic inflammation signaling, and defense mechanisms associated with e-cigarette exposure (Reidel et al., 2018; Staudt et al., 2018). In patients with COPD, the use of e-cigarettes has been associated with more cough and phlegm, more exacerbations and possibly a more rapid decline in lung function (Bowler et al., 2017).

Cardiovascular system: Cardiovascular disease is the major cause of death among smokers (Askin et al., 2017) e-cigarette use acutely and negatively (increased) impacted vital signs, such as heart rate and blood pressure (Yan et al., 2015). E-cigarette has been associated with paroxysmal atrial fibrillation (PAF) and acute myocardial infarction in cardiovascular system (Monroy et al., 2012) e-cigarette vapor extracts were found to enhance activation (aggregation and adhesion) of platelets which is important step in progression of atherosclerosis (Hom et al., 2016). Cigarette smoking can cause coronary spasm and is a risk factor for vasospastic angina. (U. s. Department of Health and Human Services Staff, 2010). However some studies show that Electronic cigarettes deliver nicotine without combustion of tobacco and appear to pose low cardiovascular risk in short term usage (Benowitz and Burbank, 2016). E-cigarette use did not have any effect on complete blood count (Flouris et al., 2012). 
Central Nervous System: E-cigarettes may also directly damage neurons and cause tremor and muscle spasms (Grana et al., 2014). As for the central nervous system, e-cigarettes may alter brain functions, which affects the mood, learning abilities, memory, and could even induce drug dependence in both humans and animals (Yuan et al., 2015). At low doses, nicotine is a weak analgesic, but at high doses, it causes tremors and seizures (Schraufnagel, 2015).

Gastrointestinal Tract: Nicotine causes peptic ulcer and gastrointestinal cancers (Chu et al., 2013). Chronic exposure of cigarette smoke induces systemic hypoxia leading to intestinal dysfunction causing Crohn's disease(Fricker et al., 2018).

Reproductive system: Exposure to nicotine in utero causes decreased birth weight, prematurity, neonatal morbidity, and mortality, including sudden infant death syndrome (Cliver et al., 1995) .Nicotine is associated with erectile dysfunction and decreased sexual arousal. (Harte and Meston, 2008). E-cigarettes have been found to have less harmful alternatives than tobacco cigarettes and are perceived as safe to use during pregnancy by pregnant women (Kahr et al., 2015).

E-Cigarettes Ban in India: The long-term health effects of e-cigarettes have not yet been documented in humans; however, the short-term negative effects causing deleterious effects on multiple biological systems have been suggested by several studies.The most powerful tools to reduce tobacco use have been increased taxes, bans on smoking in public places, and denormalizing its use. Tobacco and nicotine always possess various health related risk.In India, a proposal to ban electronic cigarettes has gained momentum and a bill has been passed to stop production, trade and transport e-cigarettes by the Union Government of India in September 2019 (Balaji, 2019).

\section{CONCLUSION}

E-cigarettes have been associated with biological effects and many health related effects in consumers . Although few studies claim it can be used as an alternative to conventional smoking, there are many studies which contradict by showing various adverse health effects. Strict rules and regulations should be enforced on usage of e-cigarettes

\section{ACKNOWLEDGEMENTS}

Nil

Conflict of Interest: None declared

\section{REFERENCES}

Arrazola RA, Singh T and Corey CG (2015) Tobacco use among middle and high school students-United States, 2011-2014. MMWR. Morbidity and mortality weekly report. ncbi.nlm.nih.gov. Available at: https:// www.ncbi.nlm.nih.gov/pmc/articles/pmc5779546/. Ash UK (2016) Use of electronic cigarettes among children in Great Britain.

Askin A, Buddemeier B, Alai M, et al. (2017) Centers for Disease Control and Prevention (CDC) Radiation Hazard Scale Data Product Review Feedback Report. DOI: $10.2172 / 1399754$.

Asma S, Mackay J, Song SY, et al. (n.d.) The GATS Atlas. Atlanta, GA: CDC Foundation, 2015 [citado mayo 29, 2018].

Balaji SM (2019) Electronic cigarettes and its ban in India. Indian journal of dental research: official publication of Indian Society for Dental Research 30(5): 651.

Benowitz NL (2011) Smokeless tobacco as a nicotine delivery device: harm or harm reduction? Clinical pharmacology and therapeutics 90(4): 491-493.

Benowitz NL and Burbank AD (2016) Cardiovascular toxicity of nicotine: Implications for electronic cigarette use. Trends in cardiovascular medicine 26(6): 515-523.

Bowler RP, Hansel NN, Jacobson S, et al. (2017) Electronic Cigarette Use in US Adults at Risk for or with COPD: Analysis from Two Observational Cohorts. Journal of general internal medicine 32(12): 1315-1322.

Brown J, Beard E, Kotz D, et al. (2014) Real-world effectiveness of e-cigarettes when used to aid smoking cessation: a cross-sectional population study. Addiction 109(9). Wiley Online Library: 1531-1540.

Bulletin of the World Health Organization (n.d.) 84(1). DOI: $10.2471 /$ blt.06.01.

Cheng T (2014) Chemical evaluation of electronic cigarettes. Tobacco control 23 Suppl 2: ii11-7.

Chu K-M, Cho CH and Shin VY (2013) Nicotine and gastrointestinal disorders: its role in ulceration and cancer development. Current pharmaceutical design 19(1): 5-10.

Cliver SP, Goldenberg RL, Cutter GR, et al. (1995) The effect of cigarette smoking on neonatal anthropometric measurements. Obstetrics and gynecology 85(4): 625-630.

Daynard R (2018) Public health consequences of e-cigarettes: a consensus study report of the National Academies of Sciences, Engineering, and Medicine. Journal of Public Health Policy. DOI: 10.1057/s41271018-0132-1.

Eisenberg M, Afilalo J, Joza J, et al. (2018) Cardiology Board Review and Self-Assessment: A Companion Guide to Hurst's the Heart. McGraw Hill Professional.

Flouris AD, Poulianiti KP, Chorti MS, et al. (2012) Acute effects of electronic and tobacco cigarette smoking on complete blood count. Food and chemical toxicology: an international journal published for the British 
Industrial Biological Research Association 50(10): 3600-3603.

Fricker M, Goggins BJ, Mateer S, et al. (2018) Chronic cigarette smoke exposure induces systemic hypoxia that drives intestinal dysfunction. JCI insight 3(3). ncbi.nlm. nih.gov. DOI: 10.1172/jci.insight.94040.

Gornall J (2015) Public Health England's troubled trail. BMJ 351: h5826.

Grana R, Benowitz N and Glantz SA (2014) E-cigarettes: a scientific review. Circulation 129(19). Am Heart Assoc: 1972-1986.

Harte CB and Meston CM (2008) Acute effects of nicotine on physiological and subjective sexual arousal in nonsmoking men: a randomized, double-blind, placebocontrolled trial. The journal of sexual medicine 5(1): 110-121.

Hom S, Chen L, Wang T, et al. (2016) Platelet activation, adhesion, inflammation, and aggregation potential are altered in the presence of electronic cigarette extracts of variable nicotine concentrations. Platelets. DOI: 10.3109/09537104.2016.1158403.

India. Ministry of Health and Family Welfare (2007) Annual Report. Government of India, Ministry of Health and Family Welfare.

Institute of Medicine, Board on Health Promotion and Disease Prevention and Committee to Assess the Science Base for Tobacco Harm Reduction (2001) Clearing the Smoke: Assessing the Science Base for Tobacco Harm Reduction. National Academies Press.

Kahr MK, Padgett S, Shope CD, et al. (2015) A qualitative assessment of the perceived risks of electronic cigarette and hookah use in pregnancy. BMC public health 15: 1273.

King BA, Gammon DG, Marynak KL, et al. (2018) Electronic Cigarette Sales in the United States, 20132017. JAMA: the journal of the American Medical Association 320(13): 1379-1380.

Machuca G, Rosales I, Lacalle JR, et al. (2000) Effect of cigarette smoking on periodontal status of healthy young adults. Journal of periodontology 71(1): 73-78. McMillen RC, Gottlieb MA, Shaefer RMW, et al. (2014) Trends in electronic cigarette use among US adults: use is increasing in both smokers and nonsmokers. Nicotine \& tobacco research: official journal of the Society for Research on Nicotine and Tobacco 17(10). Society for Research on Nicotine and Tobacco: 1195-1202.

Monroy AE, Hommel E, Smith ST, et al. (2012) Paroxysmal atrial fibrillation following electronic cigarette use in an elderly woman. Clinical geriatrics 20(3). HMP Communications LLP: 28-32.

Okamoto Y, Tsuboi S, Suzuki S, et al. (2006) Effects of smoking and drinking habits on the incidence of periodontal disease and tooth loss among Japanese males: a 4-yr longitudinal study. Journal of Periodontal Research. DOI: 10.1111/j.1600-0765.2006.00907.x.

Pearson JL, Reed DM and Villanti AC (2020) Vapes, E-cigs, and Mods: What Do Young Adults Call E-cigarettes? Nicotine \& tobacco research: official journal of the Society for Research on Nicotine and Tobacco 22(5): 848-852.

Pintado-Palomino K, de Almeida CVVB, Oliveira-Santos C, et al. (2019) The effect of electronic cigarettes on dental enamel color. Journal of Esthetic and Restorative Dentistry. DOI: 10.1111/jerd.12436.

Polosa R, Morjaria J, Caponnetto P, et al. (2014) Effect of smoking abstinence and reduction in asthmatic smokers switching to electronic cigarettes: evidence for harm reversal. International journal of environmental research and public health 11(5): 4965-4977.

Preber H, Linder L and Bergström J (1995) Periodontal healing and periopathogenic microflora in smokers and non-smokers. Journal of clinical periodontology 22(12): 946-952.

Rad M, Kakoie S, Niliye Brojeni F, et al. (2010) Effect of Long-term Smoking on Whole-mouth Salivary Flow Rate and Oral Health. Journal of dental research, dental clinics, dental prospects 4(4): 110-114.

Reidel B, Radicioni G, Clapp PW, et al. (2018) E-Cigarette Use Causes a Unique Innate Immune Response in the Lung, Involving Increased Neutrophilic Activation and Altered Mucin Secretion. American journal of respiratory and critical care medicine 197(4): 492-501.

Reuther WJ, Hale B, Matharu J, et al. (2016) Do you mind if I vape? Immediate effects of electronic cigarettes on perfusion in buccal mucosal tissue--a pilot study. The British journal of oral \& maxillofacial surgery 54(3): 338-341.

Schraufnagel DE (2015) Electronic Cigarettes: Vulnerability of Youth. Pediatric allergy, immunology, and pulmonology 28(1): 2-6.

Shirodaria S, Smith J, McKay IJ, et al. (2000) Polymorphisms in the IL-1A Gene are Correlated with Levels of Interleukin-1 $\alpha$ Protein in Gingival Crevicular Fluid of Teeth with Severe Periodontal Disease. Journal of dental research 79(11). SAGE Publications Inc: 1864-1869.

Singh T, Agaku IT, Arrazola RA, et al. (2016) Exposure to Advertisements and Electronic Cigarette Use Among US Middle and High School Students. Pediatrics 137(5). DOI: $10.1542 /$ peds.2015-4155.

Singh T, Arrazola RA, Corey CG, et al. (2016) Tobacco Use Among Middle and High School Students - United States, 2011-2015. MMWR. Morbidity and Mortality Weekly Report. DOI: 10.15585/mmwr.mm6514a1.

Staudt MR, Salit J, Kaner RJ, et al. (2018) Altered lung biology of healthy never smokers following acute 
inhalation of E-cigarettes. Respiratory research 19(1): 78.

Sundar IK, Yao H and Rahman I (2013) Oxidative stress and chromatin remodeling in chronic obstructive pulmonary disease and smoking-related diseases. Antioxidants $\&$ redox signaling. liebertpub.com. Available at: https:// www.liebertpub.com/doi/abs/10.1089/ars.2012.4863.

U. S. Department of Health and Human Services Staff (2010) How Tobacco Smoke Causes Disease: The Biology and Behavioral Basis for Smoking-Attributable Disease : A Report of the Surgeon General. U.S. Department of Health and Human Services, Public Health Service, Office of the Surgeon General.

Vakkalanka JP, Hardison LS and Holstege CP (2014) Epidemiological trends in electronic cigarette exposures reported to U.S. Poison Centers. Clinical toxicology 52(5). Taylor \&t Francis: 542-548.
Villanti AC, Johnson AL, Ambrose BK, et al. (2017) Flavored Tobacco Product Use in Youth and Adults: Findings From the First Wave of the PATH Study (20132014). American journal of preventive medicine 53(2): 139-151.

Wallace RH (2000) The relationship between cigarette smoking and dental implant failure. The European journal of prosthodontics and restorative dentistry 8(3): 103-106.

Yan XS, Sherwin Yan X and D'Ruiz C (2015) Effects of using electronic cigarettes on nicotine delivery and cardiovascular function in comparison with regular cigarettes. Regulatory Toxicology and Pharmacology. DOI: 10.1016/j.yrtph.2014.11.004.

Yuan M, Cross SJ, Loughlin SE, et al. (2015) Nicotine and the adolescent brain. The Journal of Physiology. DOI: 10.1113/jp270492. 